ФИЛОЛОГИЧЕСКИЕ НАУКИ. ЛИНГВИСТИКА

DOI: $10.26907 / 2074-0239-2020-60-2-7-11$

УДК 811.161.1

\author{
ТЕКСТ ДЛЯ СПЕЦИАЛЬНЫХ ЦЕЛЕЙ \\ В ПРОФЕССИОНАЛЬНОМ ДИСКУРСЕ
}

\author{
(С) Юлия Агеева, Ван Мо
}

\title{
TEXT FOR SPECIFIC PURPOSES IN PROFESSIONAL COMMUNICATION
}

\begin{abstract}
Julia Ageeva, Wang Mo
The paper focuses on the text as a tool for professionally oriented teaching of Russian as a foreign language. When designing an optimal educational course for international students in the language of their university major, we face the methodological problem of determining the type of text material. The paper attempts to solve this issue by studying and considering fundamental characteristics of a scientific text which acts as a unit in teaching communication in Russian based on professional discourse. In this regard, the article defines the terms scientific text, professional discourse and presents lexical, grammati$\mathrm{cal}$, logical and semantic aspects of scientific texts. The main features of a professionally oriented text are contextually illustrated by texts from the course book for students who major in International Relations. The characteristic feature of the lexis in such text is the presence of three layers of vocabulary - commonly used, general scientific and terminological vocabulary. One of the important distinguishing features of the scientific text in terms of grammar is the use of a certain system of linking elements. Concentration of information is a typical feature of modern scientific texts. The final part of the paper provides the summary and directions for further research.
\end{abstract}

Keywords: textocentrism, scientific text, professional discourse, Russian for specific purposes, international students.

В фокусе внимания авторов статьи находится текст как средство профессиональноориентированного обучения русскому языку в иностранной аудитории. В методической практике при создании оптимальной учебной разработки по языку специальности для иностранных студентов возникает проблема определения типа текстового материала. В статье предпринята попытка решения данной проблемы путем изучения и учета основных характеристик текста научной направленности, который выступает в качестве единицы обучения русскоязычному общению в профессиональном дискурсе. В связи с этим дается определение «научного текста», «профессионального дискурса», представлены характеристики научного текста в лексическом, грамматическом и логико-смысловом аспектах, проиллюстрированные примерами из учебника по специальности «Международные отношения». Спецификой лексического состава подобных текстовых материалов является наличие трех пластов лексики - общеупотребительной, общенаучной и собственно научной, терминологической. Одной из важных отличительных черт научного текста в грамматическом плане можно считать использование определённой системы соединительных элементов, концентрация изложения информации в тексте является типичной чертой современных произведений в научном стиле. В заключительной части статьи подводятся итоги работы и рассматривается направление дальнейшего исследования.

Ключевые слова: текстоцентризм, научный текст, профессиональный дискурс, русский язык для специальных целей, иностранные студенты.

XXI век ознаменовался повышением интереса к изучению иностранного языка как компонента профессиональной подготовки в связи с происходящим в современном мире научно- техническим прогрессом, а также активизацией международного общения во всех сферах человеческой деятельности. Данный процесс происходит и в сфере изучения русского языка как 
иностранного (далее - РКИ), что объясняется увеличением количества иностранцев, проходящих обучение по различным гуманитарным и негуманитарным направлениям в российских вузах. Знание языка изучаемой специальности необходимо студентам, чтобы эффективно работать на занятиях по дисциплинам, включенным в учебный план: читать и понимать научную литературу по специальности, извлекать и обрабатывать нужную информацию, отвечать на вопросы преподавателей-предметников, обсуждать проблемы и дискутировать на семинарах, выступать с научным докладом по специальности, публиковать статьи и т. д. Умения и навыки по русскому языку для специальных целей становятся все более актуальными для иностранных студентов и в дальнейшей профессиональной дискурсивной коммуникации. В связи с этим в неязыковых и многопрофильных вузах уделяют все более пристальное внимание обучению будущих специалистов общению в рамках русскоязычного учебно-профессионального дискурса.

В ходе исследования методов и приёмов построения учебных пособий было отмечено, что в ряду актуальных методических проблем имеет место недостаточно чёткое определение принципов организации учебных материалов по языку специальности (в частности профиль «Международные отношения»), целью которых является обучение профессиональной коммуникации. Проанализировав большое количество учебнометодической литературы, посвященной текстоцентрической концепции в обучении РКИ, мы пришли к выводу об основополагающей роли текстоцентрического подхода, предполагающего рассмотрение текста как центральной единицы в структуре и содержании профессиональноориентированного учебного материала. Был также сделан вывод о том, что проблема, связанная с ответом на вопрос «Какой именно текст считается наиболее адекватным целям преподавания русского языка в профессиональном дискурсе?», до сих пор не имеет оптимального решения.

Цель настоящей работы - определение типа текстового материала, перспективного для решения задач обучения РКИ в профессиональном дискурсе (на примере специальности «Международные отношения»), выделение и представление его характеристик, без учёта которых невозможно создание успешных методических разработок, построенных на основании текстоцентрического подхода.

По нашему мнению, одним из наиболее важных средств обучения (в случае профессионально-ориентированного обучения) является научный текст. Данное положение, с одной стороны, определяется сущностью текстов научной направленности, предназначенных прежде всего для передачи объективной информации в различных сферах деятельности, в том числе профессиональной; с другой - оно обусловлено эффективностью работы с данным видом текста при формировании умений и навыков профессионального общения на русском языке. Изучение научных текстовых материалов по определённому направлению способствует овладению средствами языка, типичными для профессиональной речи; пониманию специфики употребления данных языковых средств при восприятии, воспроизведении, порождении русскоязычного учебного текста, который имеет общенаучный или узкоспециальный характер, а также развивает способность определять вид коммуникативной ситуации, находить адекватные средства и формы речевого поведения.

Исследуемый тип текста представляет собой последовательный порядок рассуждений, аргументов, тезисов, определений, гипотез. Если рассматривать его с точки зрения содержания, то текст является единством, в котором доказательным способом раскрывается содержание рассматриваемого предмета, приводится общая закономерность его характеристик в различных аспектах. Другими словами, в тексте всегда раскрывается содержание определённой темы в рамках специальности, предполагается членение на подтемы.

В одной из наиболее развёрнутых дефиниций текст научной направленности определен как «интегральный феномен, взаимосвязанное и взаимообусловленное единство четырёх секторов: когнитивного, языкового, культурного и социального, функционирующее как единое целое с помощью механизма коммуникативной деятельности» [Хомутова]. Таким образом, если исходить из представленного определения, в понятие научного текста входит элемент реального общения; значит, в текст научного характера включаются не только лингвистические, но и экстралингвистические элементы, чем также обеспечивается статус текста данного вида в обучении иноязычному общению в определённом профессиональном дискурсивном контексте. Профессиональный дискурс в рамках нашего исследования понимается как «одна из разновидностей институционального дискурса, общение профессионалов в качестве представителей социальных групп с целью выполнения социально значимых задач на рабочем месте» [Ван Мо, c. 20].

Далее следует отметить, что научный текст имеет ряд присущих ему лексических, граммати- 
ческих и логико-смысловых особенностей, знание которых способствует эффективной работе преподавателей и студентов с данным видом текстового материала в учебном процессе и в профессиональном общении, и, что самое главное, учет этих особенностей способствует правильному выбору текстов для решения конкретных учебных целей. Проанализируем их подробнее.

В научных текстах встречаются три основных лексических пласта общеупотребительной, общенаучной и собственно терминологической лексики по специальности. Первый - общеупотребительная лексика, функционирующая в качестве основы всех разновидностей речи, обладает максимальной частотностью и является в полной мере нейтральной в отношении стиля и автора. Второй пласт - общенаучная лексика, как правило, выполняющая функцию информирования о результатах познавательной деятельности человека. Общенаучная лексика составляет основу научных текстов, имеет отличительные черты большую гибкость и «подвижность». Третий лексический слой представлен собственно терминологической лексикой, «обозначающей понятия специальной области знания или деятельности» [Лингвистический энциклопедический словарь, с. 508]. Наличие терминов - это безусловный признак текстов научной направленности, так как каждая научная отрасль имеет свою терминологию. Рассмотрим пример № 1 (отрывок из учебника по специальности «Международные отношения», тема «Политическая карта мира после окончания холодной войны»):

Окончание х о лодн о й в о йн ы в Европе совпало с радикальными переменами в нутр и пол и тической жизни стран Организации Варшавского договора (ОВД). Эти изменения принято связывать с чередой т. н. «барх а ных ре волюций » в Восточной Европе осенью 1989 г. Последние были спровоцированы как несоответствием в осточн оев ропей ских режи мов требованиям времени, так и отказом весной 1989 г. с о в е тского лиде p а М. С. Горбачева от так называемой «доктри ны Брежнев а (западное понятие, подразумевавшее «узаконенную» практику вмешательства СССР во внутренние дела стран ОВД) [Хмылёв, с. 34] (здесь и далее разрядка наша - Ю. А., В. М.).

В представленном абзаце отмечается общеупотребительная лексика - жизнь, требование, время, отказ, дела и т. п.; общенаучные слова изменение, режим, понятие, практика, а также узкоспециальная лексика (термины) - холодная война, внутриполитическая жизнь, «бархатная револючия», восточно-европейский режим, со- ветский лидер, «доктрина Брежнева» и др. Очевидно, что общенаучные слова и термины занимают большую долю лексического состава текста.

Употребление терминологии является «наиболее бросающейся в глаза, но не единственной особенностью текстов научного стиля» [Арнольд, с. 167]. В качестве основной грамматической (или синтаксической) характеристики исследуемого типа текста можно выделить использование определённой системы соединительных элементов, вытекающей из строго выстроенной логической последовательности изложения. Логический синтаксис также является одной из важных отличительных черт научного текста. Употребление вводных конструкций вызвано необходимостью аргументации мнения автора (указание на его субъективность или объективность), а также целью более четкой структуризации и логического построения текста. Проиллюстрируем данный факт примерами из текста «К истории и методологии понятия международных отношений», где отмечены такие вводные слова и словосочетания, как прежде всего, вероятно, как известно и др.:

Международные отношения - это, прежде в с ег о, стихийно организованные отношения крупных национальных государств [Хмылёв, с. 8].

В е р о я т н о, главным признаком эффективности внешней политики государства является эквивалентный и справедливый характер его ресурсного обмена с внешним миром; отметим, при этом, что оценка этой эквивалентности всегда очень субъективна, поскольку зависит от интеллектуальных характеристик субъектов международных отношений [Там же, с. 10].

К а к из в естно, представление об окружающем мире человек получает из шести информационных каналов. Это - зрение, слух, обоняние, ощущение, вкус и, шестой канал, - язык, который в текстовом виде через какой-то один канал информации может передать содержание всех остальных [Там же, c. 15].

Кроме того, типичной чертой современных произведений в научном стиле является концентрация информации. Компактность изложения материала осуществляется различными средствами, в том числе, например, с помощью аббревиатур и сокращений (см. пример №1: ОВД, $C C C P$, т.н.), а также атрибутивных конструкций, которые могут включать в себя одни существительные либо же существительные в паре с прилагательными, причастиями, числительными, словосочетаниями, которые определяют одно понятие. Рассмотрим пример № 2 (также из тек- 
ста «Политическая карта мира после окончания холодной войны»), в котором отмечены такие конструкции:

В столице Румынии Бухаресте произошли в о о руженные столкновения войск с де м о н с т р а н т а и , пролилась кровь тысяч невинных людей. На каком-то этапе развития полити ч еского кризиса инициатива перешла в руки оппозиции, и Н. Чаушеску вместе со своей женой бежал из столицы. Но вскоре они попали в руки «революционного» правосудия и после скорого суда были расстреляны [Там же, с. 34].

Интересно, что в данном отрывке атрибутивные группы в основном состоят из цепочки определений - специальных терминов: вооруженные столкновения войск с демонстрантами, этап развития политического кризиса и т. п.

Нельзя проигнорировать и особенности структуры научных произведений, когда весьма строгим является деление текста на абзацы. В каждом последующем абзаце продолжается мысль предыдущего, «непосредственно вытекает из него и имеет связующие элементы» [Гальперин, с. 426]. Важно учесть наличие ключевого предложения (излагающего основную мысль текста) в начале каждого абзаца. Представляем пример № 3 из темы «Центры влияния в современном мире»:

«Прежде всего определимся с понятиями однополярности, биполярности и многополярности международных отношений.

Однополярными м международные отношения становятся в том случае, если в мире возникает единственный центр управления глобальными экономическими и политическими проц е с с а м и . По замечанию В. В. Путина, однополярный мир - это мир «одного хозяина, одного центра принятия решений». <..>.

Биполярные международные отно шения возникают тогда, когда в ире господствует два примерно равных центра силы, два центра экономиче ского или военно-политического при тяжения, вокруг которых образуется коалиция зависимых или полузависи мых государств. Биполярность - явление прежде всего XX в., в котором такая модель международных отношений соответствовала периодам масштабной военной или военно-политической конфронтации между группами государств. <..>.

Многополярными международные отношения можно назвать тогда, ко гда вияе начинает действовать не сколько примерно равных по эконо мическому, политическому и военному потенциалу субъектов глобальной п о л и т и к и . Исторически данный тип международных отношений был преобладающим и обычно сопутствовал относительно спокойным историческим периодам. $<\ldots .>$.

Рассмотрим, какое из названных понятий, по мнению современных учёных и политиков, соответствует нынешнему этапу развития международных отношений [Хмылёв, с. 35-36].

В данном примере с помощью абзацев текст делится на три смысловые части: первая - абзац 1, вторая - абзац 2, 3, 4 и третья - абзац 5. Часть вторая (основная в данном отрывке) раскрывает содержание части первой, в ней мысль вытекает последовательно одна за другой. Внутри части 2 первая фраза каждого абзаца - его смысловой центр. Третья часть является логическим переходом к следующей информации.

Таким образом, наличие перечисленных характеристик текста по специальности может стать одним из главных критериев при отборе текстовых материалов.

Итак, в настоящей работе обоснована важная роль научного текста в процессе обучения русскоязычному общению в профессиональном дискурсе с позиции текстоцентрического подхода, который определяется как наиболее перспективное и продуктивное направление в современной методике преподавания русского языка для специальных целей в пределах университетского образования. Выявлены и проиллюстрированы примерами основные характеристики текстов, которые необходимо учитывать при разработке учебных материалов, предназначенных иностранным студентам определённой специальности. Для создания учебного материала нового поколения необходимо решить ещё ряд вопросов, например, какие научные тексты следует отбирать с учётом разного уровня языковой подготовки иностранных учащихся - аутентичные или адаптированные, какая должна быть степень адаптированности текста и т. п. Данные проблемы требуют более голубого изучения в дальнейшем.

\section{Список литературы}

Арнольд И. В. Стилистика. Современный английский язык: учебник для вузов. 4-е изд., испр. и доп. М.: Флинта: Наука, 2002. 384 с.

Ван Мо. Объявление как жанр профессионального дискурса // Филология и культура. Philology and culture. 2019. №1(55). С. 18-21.

Гальперин И. Р. Очерки по стилистике английского языка. М.: Изд. лит-ры на иностр. яз., 1958. 459 с.

Лингвистический энциклопедический словарь. М.: Сов. энцикл. 1990. 682 с. 
Хмылёв В. Л. Современные международные отношения: учебное пособие. Томск: Изд-во Томского политического университета, 2010. 210 с.

Хомутова T. Н. Научный текст: интегральный анализ лексики // Язык и культура. 2010. № 4 (12). URL: https://cyberleninka.ru/article/n/nauchnyy-tekstintegralnyy-analiz-leksiki (дата обращения: 30.02.2020).

\section{References}

Arnol'd, I. V. (2002). Stilistika. Sovremennyi iangliiskii iazyk: Uchebnik dlia vuzov. 4-eizd., ispr. i dop. [Stylistics. Modern English Language: A College Textbook. $4^{\text {th }}$ edition]. 384 p. Moscow, Flinta, Nauka. (In Russian)

Gal'perin, I. R. (1958). Ocherki po stilistike angliiskogo jazyka [Essays on Stylistics of the English Language]. 459 p. Moscow, izd. lit-ry na inostr. iaz. (In Russian)

\section{Агеева Юлия Викторовна,}

доктор филологических наук, профессор,

Казанский федеральный университет, 420008, Россия, Казань,

Кремлевская, 18.

jagreeva@yandex.ru

\section{Ван Мо,}

аспирант,

ассистент,

Казанский федеральный университет, 420008, Россия, Казань,

Кремлевская, 18.

WangMo1992@yandex.ru
Lingvisticheskii entsiklopedicheskii slovar (1990) [Encyclopedia of Linguistics]. 682 p. Moscow, Sovetskaia e`ntsiklopediia. (In Russian)

Hmyliov, V. L. (2010). Sovremennye mezhdunarodnye otnosheniia: uchebnoe posobie [Modern International Relations: A Textbook]. 210 p. Tomsk, Izdvo Tomskogo politikhnicheskogo universiteta. (In Russian)

Khomutova, T. N. (2010). Nauchnyi tekst: integral'nyi analiz leksiki [Research Text: Integral Analysis of Lexis]. Iazyk i kul'tura, No. 4 (12), URL: https://cyberleninka.ru/article/n/nauchnyy-tekstintegralnyy-analiz-leksiki (accessed: 30.02.2020). (In Russian)

Van, Mo (2019). Obiavlenie kak zhanr professional'nogo diskursa [Announcement as a Genre of Professional Discourse]. Filologiia I kul'tura. Philology and culture, No. 1(55), pp. 18-21. (In Russian)

The article was submitted on 24.04.2020

Поступила в редакцию 24.04.2020

\author{
Ageeva Julia Victorovna, \\ Doctor of Philology, \\ Professor, \\ Kazan Federal University, \\ 18 Kremlyovskaya Str., \\ Kazan, 420008, Russian Federation. \\ jagreeva@yandex.ru
}

\section{Wang Mo,}

graduate student,

Assistant Professor,

Kazan Federal University,

18 Kremlyovskaya Str.,

Kazan, 420008, Russian Federation.

WangMo1992@yandex.ru 